\title{
Role of Mathematical Competencies in Enhancing Students' Academic Performance in Physics in Port Harcourt Local Government Area Rivers State
}

\author{
Omeodu M. Doris, Ph.D \\ Department of Science Education Rivers State University, \\ Port Harcourt, Nigeria
}

URL:http://dx.doi.org/10.19044/esj.2019.v15n21p59

\begin{abstract}
The study investigated "Role of Mathematical Competencies in Enhancing Students' academic Performance in Physics in Port Harcourt Local Government Area Rivers State". The study specifically sought to determine; the mathematical competencies of Physics students, the mean score of students with high mathematical competencies (HMC), medium mathematical competencies (MMC), and low mathematical competencies (LMC) in Physics, and also the mean difference that exists between the performance of students with HMC, MMC and LMC in Physics. The study adopted correlation design. The total number of S.S.3 science students in these four schools was 76 students but due to certain circumstances during the time of the study, only 62 of the students were present and used in the study. The instrument used in the study was mathematics achievement test and physics achievement test. In MCT, students who scored 40 below were grouped as those who have low mathematical competencies, those who scored 41-69 were grouped as medium mathematical competencies while those who score 70 above were grouped as those with high mathematical competencies. Both tests were score and analyzed using mean and standard deviation. The hypothesis was tested using Pearson Product Moment Correlation Coefficient PPMC at 0.05 level of significance. The study found that $22.58 \%$ of respondents have HMC, $30.65 \%$ has MMC and majority of them has LMC $46.77 \%$. The study also found that students with HMC performed significantly better than those with MMC and LMC in Physics tests. The hypothesis confirmed that there was a strong positive correlation between mathematical competency and performance in physics. The researcher therefore recommends that science students should strive hard to be adequately competent in subjects involving abstract logical reasoning and numeric calculations as this may enhance their overall academic performance.
\end{abstract}


Keywords: Competence, Mathematics, Physics, Achievement

\section{Introduction}

The advancement in technology in recent years has created a pace at which science becomes indispensable in all hemisphere of the modern society. At the heart of science lies Physics and Physics necessitates mathematical competence (Redish, 2006). Physics is one of the major natural science subjects that supplies the knowledge of the physical environment and matter to the learner. In the understanding of matter and its properties, mathematical analysis is inevitable because it has dealings with numeric entities. Therefore, the society has advanced in the manipulation of matter for beneficial uses because of the advanced understanding in the interaction of matter, force and energy. Physics serves as one of the most effective tool science uses to interact or utilize matter to meet human needs.

Physics is the study of systematized knowledge produced by observation, measurement and experiment which attempts to establish general laws or principles to describe the phenomena under study (Ivowi, 1999). Physics as described by Raspanti (2003) is a methodical study of nature based on observation, reason and mathematical analysis. Since Physics derive its name from the word 'nature' which made to be earlier called natural philosophy, it helps to understand the fundamental building block of the universe and how nature interact. It deals with fundamental elements such as matter, energy, motion and force. Ibibo and Francis (2017) defined physics as a science that involves the study of the physical properties of matter and its interaction with energy a study of systematized knowledge produced by careful observation, measurement, and experiment in a view to establishing basic laws as well as give scientifically reliable explanation to natural phenomena.

Mathematics is often referred to as "language of science'". Although, there is no universal agreement even among the experts on the acceptable definition of mathematics. But, some found it to be a mental activity that deals with quantity, symbolic logic and carries out constructs one after the other in numeric terms. Mathematics is closely related to natural science in such that it is a language science uses to convey its observation, experimentation and conclusion. It is a science of structure, order and relation that has evolved from elemental practices of counting, measuring and describing the shapes of objects (Fraser, Gray, Knorr, Folkerts, \& Berggren 2004). Physicists have agreed that theory of relativity was so acceptable in physics because of its great mathematical beauty despite the fact of its going against principle of simplicity that governs physics. According to Maton (2014) mathematics is a tool for epistemological condensation because it tends to encode technicality 
in language. However, Adeyemi (2007) in his study "mathematics as a language for involving secondary school children in science and technology", concluded that student performance in West African schools certificates examination (SSCE) in mathematics highly correlates with their performance in Physics in the same examination which remained generally poor. Even in the western world Mullis (2009) has observed that students performance in the subjects involving logical reasoning and calculation such as mathematics and physics in upper secondary school are in continued decline in a number of countries which includes Sweden and Norway. Poor grounding in mathematics is manifested in their overall performance in physics which over the years have faced a continuous downward trend in Senior Secondary School Certificate Examination results. (Awofala, Ogunleye, \& Adekoya , 2014)

Science students must not only read mathematics as it is used in classrooms, textbooks and assessment, and in doing so, gain technical physical meaning, they must also consider mathematics as a means to solving physical problems (Doran, 2017). Without the strong potential for condensation, technical meanings would have a limited possibility for relativity to the physical problems, meaning they would be tied to their contexts and become segmentalized. Physics would thus lose the potential to develop generalizable theories that account for a broad range of phenomena. Mathematics is foundational to science and engineering, and it has been argued that "the best 'practical' approach to mathematics is to understand it as a language for describing physical and chemical laws (Sazhin, 1988). Nakakoji and Wilson (2018) when observing the relationships between General Educational Attainment (University Entrance Rank), Mathematics Attainment, Physics/Engineering Attainment, and the Transfer of Learning between Mathematics and Physics/Engineering found that, mathematics is central for learning in these courses; attainment in mathematics is highly related to attainment in physics/engineering. Dehipawala, Shekoyan \& Yao (2014) affirmed that mathematics is predictive of science attainment and well established in more specific models of Physics. So, Science students have to learn how to engage mathematics for structured thinking about physical processes and how to interpret mathematical structures in physical terms if they are to soar in their science attainment. Different mathematical elements or representations such as geometrical objects, diagrams, algebraic expressions and verbal explanations have their specific roles for supporting, understanding by describing exactly, quantifying and visualizing physical processes (Pospiech, 2007).

Mathematics plays both technical (calculating and solving differential equation, the semantics and physical meaning of mathematical structures) and a structural roles (formal derivation of physical laws) in physics (Pospiench, Elyon, Bagno, \& Yaron, 2015). Different mathematical elements or 
representations geometrical objects, diagrams, algebraic expressions and verbal explanation have their specific roles for supporting understanding, by describing exactly, quantifying, and visualizing physical process (Pospiench, 2007). Although, Physics draws symbols and equations from mathematics, reading and interpreting these equations are from that of mathematics and their goals are absolutely different. While mathematics just explore ways of solving equations, physics tends utilize these equations to describe, learn, and understand physical systems (Redish, 2005).

A model describing the bare bones of how mathematics is being used in physics (and in other sciences as well).

2. Process

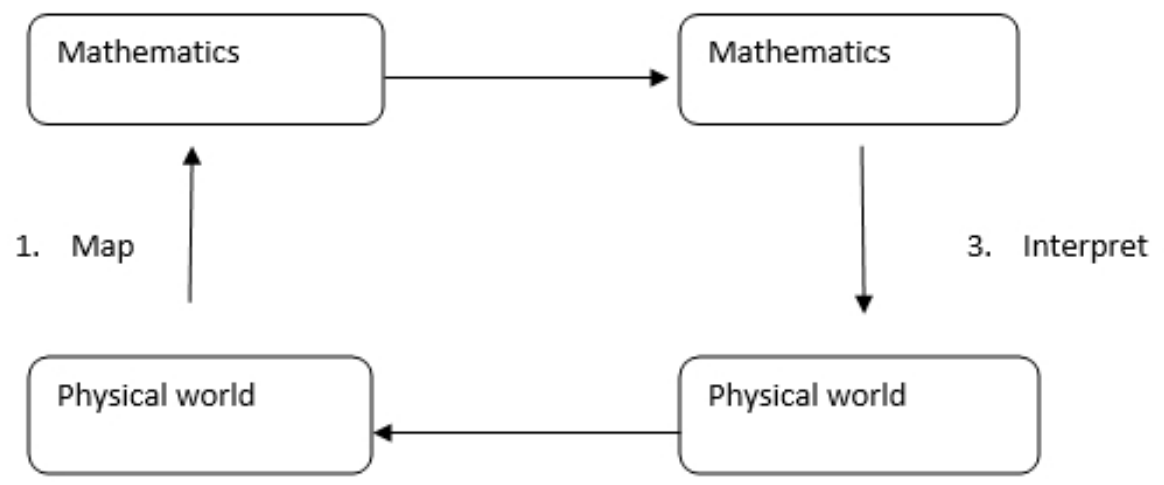

4. Evaluate

A model for the use of Maths in science

Step 1: Map. Creating a mathematical model of our physical structures. This implies selecting mathematical structures that are relevant to the physical characteristics we are trying to model. Step 2: process. The mathematical structures introduced to physical characteristics may leads to solving an equation or deriving new ones.

Step 3: interpret. The solved or derived equation will result to structures which presents physical characteristics in mathematical terms.

Step 4: evaluate. We have to evaluate whether our results adequately describe our physical system or whether we have to modify our model.

Adopted from Redish, (2005)

Tzanakis (N.D) stated that mathematics is not only the language of physics but also tools for expressing, handling and developing logically physical concepts and theories. However, researches in time which have attempted to measure the impact of high school physics courses on students' success in undergraduate physics found that students who performed well in high school mathematics and physics subjects also did well in undergraduate physics (Hart \& Cottle, 2003; Alters, 1995). Charles-Ogan and Francis (2017) 
also found in their study that that students of high mathematics abilities contributed to high performance in the concepts of electromagnetism' while those of low mathematics ability performed poorly.

Osborne, Simon and Collins (2003), Lord and Jones, (2006) maintained that physics students who lacked basic algebra performed poorly on mathematical problem-solving tasks in physics due to students lack knowledge of mathematical skills needed in problem-solving in physics or students do not know how to apply the mathematical skills they have to particularly solve the problems situation in physics. Although a wide conceptual difference exists between subjects (Physics and Mathematics) it is no longer history that mathematical knowledge is required to tackle numerical problems in physics, leaving much to be done in order to change students attitude towards mathematics and science. Therefore the study sought establishes the role of mathematical competencies on students' achievement in Physics.

\section{Purpose of the study}

The main purpose of the study is to investigate the role of mathematical competencies in enhancing Physics students' academic performance in secondary schools in PHALGA. In specific terms, the study tends to

1. Determine the mathematical competencies of Physics students with a standardized test

2. Determine the mean score of students with high mathematical competencies (HMC), medium mathematical competencies (MMC), and low mathematical competencies (LMC) in Physics

3. Determine the mean difference that exists between the performance of students with HMC, MMC and LMC in Physics

\section{Research Questions}

1. What are the mathematical competencies of Physics students using a standardized mathematics achievement test?

2. What is the mean score of students with high mathematical competencies (HMC), medium mathematical competencies (MMC), and low mathematical competencies (LMC) in Physics?

3. What is the mean difference that exists between the performances of students with HMC, MMC and LMC in Physics?

\section{Hypotheses}

- There is no significant relationship between student's mathematical competencies and their academic performance in physics. 


\section{Methodology}

The study adopted a correlation design. This design was suitable as it helps to establish the relationship between mathematical competencies and academic performance of students in Physics. Simple random sampling was used to select four science teaching secondary schools in Port Harcourt local government area. The total number of S.S.3 science students in these four schools was 76 students but due to certain circumstances during the time of the study, only 62 of the students were present and used in the research. The instrument used for this research was mathematics achievement test and physics achievement test. Each of the questions in both mathematical competencies test and physics achievement test carries 4 marks. MCT and PAT contain 25 multiple choice questions each. In MCT, Students who scored 40 below were grouped as those who have low mathematical competencies, those who scored 41-69 were grouped as medium mathematical competencies while those who score 70 above were grouped as those with high mathematical competencies. During the time of research, code number was assigned to each of the students, and they were asked to write the code number on the question papers both on mathematics and physics for easy identification and correlation. The both question papers were gathered and were scored. Mean and standard deviation was used to analyze the performance of the students and the closeness of the scores. The hypothesis was tested using Pearson Product Moment Correlation Coefficient PPMC at 0.05 level of significance, correlation coefficient value less that 0 means negative relationship, higher than 0 means positive relationship, while at 0 means no relationship exist between the variables.

\section{Result and Discussion}

Research Question one: What are the mathematical competencies of Physics students using a standardized mathematics achievement test?

Table 1: Mathematical competencies of Physics Students using standardized achievement test

\begin{tabular}{|c|c|c|c|c|}
\hline Group & $\begin{array}{c}\text { No of } \\
\text { students }\end{array}$ & $\begin{array}{c}\text { High mathematics } \\
\text { competency }\end{array}$ & $\begin{array}{c}\text { medium mathematics } \\
\text { competency }\end{array}$ & $\begin{array}{c}\text { low } \\
\text { mathematics } \\
\text { competency }\end{array}$ \\
\hline Male & 27 & 6 & 9 & $\mathbf{1 2}$ \\
\hline Female & 35 & 8 & 10 & $\mathbf{1 7}$ \\
\hline Total & $\mathbf{6 2}$ & $\mathbf{1 4}$ & $\mathbf{1 9}$ & $\mathbf{2 9}$ \\
\hline Percentage & $\mathbf{1 0 0 \%}$ & $\mathbf{2 2 . 5 8 \%}$ & $\mathbf{3 0 . 6 5 \%}$ & $\mathbf{4 6 . 7 7 \%}$ \\
\hline
\end{tabular}

Field survey

From the table 1, result shows the performance of the students in the mathematics achievement test. However, the study has it that the total of 14 students has high competency in mathematics, nineteen (19) have medium 
mathematics competency while twenty-nine (29) have low mathematics competency. It is obvious that larger percentage of the students under study have low mathematics competency and this amount the reason why there have being student's consistent poor performance in subjects that involves abstract thinking or calculation of numeric terms. This finding is in collaboration with Mullis (2009) who observed that students performance in the subjects involving logical reasoning and calculation such as mathematics and physics in upper secondary school are in continued decline in a number of countries which includes Sweden and Norway.

Research Question two: What is the physics mean score of students with HMC, MMC and LMC?

Table 2: Mean scores and standard deviation of students with HMC, MMC, and LMC in Physics.

\begin{tabular}{|c|c|c|c|}
\hline Group & No of students & Physics mean score & Standard deviation \\
\hline HMC & 14 & 73.57 & 9.02 \\
\hline MMC & 19 & 45.47 & 13.08 \\
\hline LMC & 29 & 33.10 & 8.87 \\
\hline TOTAL & $\mathbf{6 2}$ & & \\
\hline
\end{tabular}

Table 2 presents the mean and standard deviation of students with HMC, MMC and LMC. Students with high mathematical competencies were 14 with the mean score of 73.57 , students with medium mathematical competencies were 19 with the mean score of 45.47 and lastly, those with low mathematical competencies were 29 with the mean score of 33.10 . The study is in line with Charles-Ogan and Francis (2017) who found in their study that that students of high mathematics abilities contributed to high performance in the concepts of electromagnetism' while those of low mathematics ability performed poorly. Also Osborne, Simon and Collins (2003) supported the findings as their research conducted on science students showed clearly that those with high mathematical abilities supersedes their counterparts in Physics.

Research Question three: What is the difference in the Physics mean score of students with HMC, MMC, and LMC? 
Table 3: Difference in the mean score of students with HMC, MMC and LMC

\begin{tabular}{|c|c|c|c|c|c|c|}
\hline \multirow[t]{2}{*}{ Group } & \multirow{2}{*}{$\begin{array}{c}\text { No of } \\
\text { students }\end{array}$} & \multirow{2}{*}{$\begin{array}{c}\text { Physics mean } \\
\text { score }\end{array}$} & \multirow{2}{*}{$\begin{array}{l}\text { Standard } \\
\text { deviation }\end{array}$} & \multicolumn{3}{|c|}{ Mean difference } \\
\hline & & & & HMC & MMC & LMC \\
\hline HMC & 14 & 73.57 & 9.02 & 0 & 28.10 & 40.47 \\
\hline MMC & 19 & 45.47 & 13.08 & -28.10 & 0 & 12.37 \\
\hline LMC & 29 & 33.10 & 8.87 & -40.47 & -12.37 & 0 \\
\hline TOTAL & 62 & & & & & \\
\hline
\end{tabular}

Field Study, 2018

Table 3 shows the difference in the mean score of students with HMC, MMC and LMC. The study shows that the difference between the mean scores of students with HMC and MMC was 28.10; while the difference between the mean scores of students with HMC and LMC was 40.47. This implies that students with HMC performed extremely better than those of MMC and LMC. Also the difference in the mean score of students with MMC and LMC was 12.37. That is, students with MMC performed more than those students with LMC. Based on this study, it is crystal clear that mathematical competencies are principal determinants in the performance of students in Physics.

\section{Hypothesis}

Ho1: There is no significant relationship between student's mathematical competencies and their academic performance in physics

Table 4:SPSS Pearson Product Moment Correlation (PPMC) table on the relationship between students' mathematical competencies and their performance in Physics

\begin{tabular}{|c|c|c|c|}
\hline & & $\mathrm{MC}$ & PHY \\
\hline \multirow[t]{5}{*}{$\mathrm{MC}$} & Pearson Correlation & 1 & $.865 * *$ \\
\hline & Sig. (2-tailed) & & .000 \\
\hline & $\begin{array}{l}\text { Sum of Squares and Cross- } \\
\text { products }\end{array}$ & 24628.387 & 20058.323 \\
\hline & Covariance & 403.744 & 328.825 \\
\hline & $\mathrm{N}$ & 62 & 62 \\
\hline \multirow[t]{5}{*}{ PHY } & Pearson Correlation & $.865 * *$ & 1 \\
\hline & Sig. (2-tailed) & .000 & \\
\hline & $\begin{array}{c}\text { Sum of Squares and Cross- } \\
\text { products }\end{array}$ & 20058.323 & 21811.935 \\
\hline & Covariance & 328.825 & 357.573 \\
\hline & $\mathrm{N}$ & 62 & 62 \\
\hline
\end{tabular}


Table 4 shows the SPSS version 23 result on the Pearson Product Moment Correlation (PPMC) of the relationship between students' mathematical competencies and their performance in Physics. However, correlation coefficient $(r)$ of 0.865 was obtained at significant level of 0.05 . The $r$ value was subjected to $\mathrm{z}$-test for significance, the $\mathrm{z}$-cal obtained was 6.79 greater than critical value of 1.96. This implies there is a significant relationship that exists between students' mathematical competencies and their performance in Physics. In other words, students who performed well in mathematics also performed significantly well in Physics. This also implies that students' poor performance in Physics is as a result of their poor background in mathematics. The result reveals so clearly that, students can in no way perform in Physics if their background in mathematics is not rigid.

\section{Conclusion}

Based on the findings of the study, the researcher concludes that; Majority of the science student in secondary schools Port Harcourt local government are deficient in mathematics as most fell among low mathematical competence (LMC) category. Many factors may be responsible for these low performances in mathematics test, ranging from socio-economic factor, students background, nature of the school, teachers' performance, lack of adequate teaching facilities and many more.

Student who has high performance ability in mathematics test also performed extraordinarily in Physic achievement test. In other words student' mathematics competency is a major predictor to their performance in Physics, that is students who are good in carrying out logical mathematical reasoning which will also successful in Physics. PPMC was therefore used to show the relationship between students' competence in mathematics and their achievement in physics. The researcher found that there is a strong positive correlation between students' mathematical competence and their performance in Physics.

Students with high mathematical competency (HMC) performed significantly better in Physics than those of medium mathematical competency (MMC) and low mathematical competency (LMC). One may generally conclude that students who are doing well in Physics are good mathematics students.

\section{Recommendation}

The researcher recommends as thus;

- Science teaching schools who intend to improve the level of their students performance in Physics and other related science subjects should enhance the teaching and learning of mathematics. 
- Science students should strive hard to be adequately competence in subjects involving abstract logical reasoning and numeric calculations as this may enhance their overall academic performance.

- Physics teachers should understand their students' level of mathematical competence so as to enable them (physics teachers) comprehensively impact students who may be deficient in carrying out mathematical task. This may save teachers from blank assumptions that all students understand certain simply mathematical process.

\section{References:}

1. Alters, B.J. (1995). Counseling physics students: a research basis. Physics Teacher, 33, 413-415.

2. Charles-Ogan G. I., Francis O. I.(2017). Effects of Mathematics Knowledge on Physics Students Performance in Electromagnetism. International Journal of Theoretical and Mathematical Physics 7(4), 61-67.

3. Dehipawala, S. Shekoyan,V. Yao, H ().Using mathematics review to enhance problem solving skill using general physics classes. In Proceedings of the 2014 Zone 1 Conference of the American Society for Engineering Education, University of Bridgeport, CT, USA, 3-5 April 2014.

4. Doran Y. J. (2016). The role of mathematics in physics: Building knowledge and describing the empirical world. ONOMÁZEIN Número especial LSF y TCL sobre educación y conocimiento (2017): 209-226 DOI: 10.7764/onomazein.sfl.08. Department of Linguistics, The University of Sydney, Australia.

5. Hart, G.E. \& Cottle, P.D. (2003). Academic backgrounds and achievement in college physics. Physics Teachers 31, 470-475

6. Lord, P. \& Jones, M. (2006). Pupils' experiences and perspectives of the National Curriculum and assessment. Final report for the research review Slough, UK: NFER.

7. Maton, K. C. (2014) Knowledge and Knowers: Towards a realist sociology of education, London: Routledge.

8. Nakakoji, Y \& Wilson, R (2018). First-Year Mathematics and Its Application to Science: Evidence of Transfer of Learning to Physics and Engineering. Educ. Sci. 2018, 8(8)1-16

9. Ogunleye, A., Awofala, A .O. A. Adekoya, E. A. (2014). Effect of Students' Background Knowledge of Mathematics on Senior Secondary School Students' Achievement in Physics. Bulgarian journal of science education 23(6),863-880. 
10. Osborne, J. Simon, S. \& Collins, S (2003). Attitudes towards science: a review of the literature and its implications. International Journal of Science Education. 25, 1049-1079

11. Pospiench, G., Elyon, B., Bagno, E., \& Yaron, L., (2015). The Role of Mathematics for Physics Teaching and Understanding. Conference GIREP-MPTL 2014.

12. Raspanti, M. (2003). Physics for Beginners. A Novice's Guide to the Mysteries of the Universe.

13. Redish, E.F., (2005). Problem Solving and the Use of Math in Physics Courses. Invited talk presented at the conference, World View on Physics Education in 2005: Focusing on Change, Delhi, August 21-26, 2005

14. Sazhin, $S$ (1988). Teaching Mathematics to Engineering Students. International Journal of Engineering Education. 14, 145-152. 